\title{
Solid-Phase Microextraction for Determination of Anilino-Pyrimidine, Dimethylcarbamate and Thiadiazine Pesticides in Irrigation Project Surface Water
}

\author{
Clóvis F. Silva Filho, ${ }^{a, b}$ Elissandro S. Emídio ${ }^{a}$ and Haroldo S. Dórea ${ }^{*, a}$ \\ ${ }^{a}$ Departamento de Química, Universidade Federal de Sergipe, Av. Marechal Rondon, s/n, \\ Jardim Rosa Elze, 49100-000 São Cristóvão-SE, Brazil \\ ${ }^{b}$ Universidade Federal do Vale do São Francisco, Campus Petrolina, Av. José de Sá Maniçoba, s/n, \\ Centro, 56304-917 Petrolina-PE, Brazil
}

\begin{abstract}
O objetivo deste trabalho foi desenvolver um método analítico por microextração em fase sólida (SPME) para a determinação de resíduos dos pesticidas pirimetanil, pirimicarbe e buprofezina em águas superficiais de áreas de irrigação por cromatografia a gás acoplada a espectrometria de massas (GC-MS). O método SPME foi otimizado apresentando os seguintes valores: tipo de fibra (polidimetilsiloxano, PDMS $100 \mu \mathrm{m}$ ), velocidade de agitação da amostra (900 rpm), pH 7, tempo de extração (30 min) e tempo de dessorção $(7 \mathrm{~min})$. A linearidade foi estabelecida na faixa de 0,1 a $4,0 \mu \mathrm{g} \mathrm{L}^{-1}$ com coeficientes de determinação $\left(\mathrm{R}^{2}\right)>0,991$. A precisão apresentou valores de desvio padrão relativo (RSD) $<15 \%$ para os pesticidas com limites de detecção (LOD) e quantificação (LOQ) variando de 0,04 a $0,1 \mu \mathrm{g} \mathrm{L}-1$ e 0,1 a $0,2 \mu \mathrm{g} \mathrm{L}^{-1}$, respectivamente. Amostras de águas superficiais do Platô de Neópolis em Sergipe (Brasil) e do Distrito de Irrigação Senador Nilo Coelho de Petrolina em Pernambuco (Brasil) foram analisadas, encontrando valores para buprofezina de até $0,14 \mu \mathrm{g} \mathrm{L}^{-1}$ e pirimicarbe abaixo do limite de quantificação. Pirimetanil não foi detectado nas amostras.
\end{abstract}

The objective of this work was to develop a solid-phase microextraction (SPME) technique for the determination of residues of the pyrimethanil, pirimicarb and buprofezin pesticides in surface waters from irrigated areas, with analysis by gas chromatography-mass spectrometry (GC-MS). The optimized method used a $100 \mu \mathrm{m}$ polydimethylsiloxane (PDMS) fiber, agitation speed of the sample of $900 \mathrm{rpm}$ and $\mathrm{pH}$ 7.0. Extraction and desorption times were 30 and $7 \mathrm{~min}$, respectively. Linearity was achieved in the concentration range $0.1-4.0 \mu \mathrm{L} \mathrm{L}^{-1}$, and coefficients of determination $\left(\mathrm{R}^{2}\right)$ were $>0.991$. Precision, expressed as relative standard deviation (RSD), was $<15 \%$, and limits of detection (LOD) and quantification (LOQ) were in the ranges $0.04-0.1 \mu \mathrm{g} \mathrm{L}^{-1}$ and $0.1-0.2 \mu \mathrm{g} \mathrm{L}^{-1}$, respectively. Surface water samples were collected from irrigated regions of the Platô de Neópolis in Sergipe State (Brazil) and from Distrito de Irrigação Senador Nilo Coelho in Pernambuco State (Brazil). Concentrations of buprofezin were $<0.14 \mu \mathrm{g} \mathrm{L}^{-1}$, while those of pirimicarb were lower than the limit of quantification (LOQ). Pyrimethanil was not detected in the samples.

Keywords: surface water, pyrimethanil, pirimicarb, buprofezin, SPME, GC-MS

\section{Introduction}

Pesticides are substances used in agriculture to increase the quantity and quality of produce. Their inappropriate usage can lead to contamination of both surface and subterranean hydric systems. Transfer routes of pesticides to surface waters include drainage, lateral percolation, surface and subsurface run-off, erosion, drift and volatilization. ${ }^{1}$

*e-mail: hdorea@ufs.br
Brazil represents $16 \%$ of the global pesticide market, with sales of more than 780,000 tons of these materials in 2009, and occupies sixth place of the global ranking for pesticide imports, with an increase of $236 \%$ between 2000 and $2007 .{ }^{2}$ Such a situation demands the existence of control structures, as well as research to provide capacity for effective monitoring of pesticides in the environment, especially in hydric resources.

Concerns about contamination of aquatic environments are greatest when the water is used for public supply or in agricultural irrigation systems. The European Community 
(Directive 98/83/EC) has established a value of $0.1 \mu \mathrm{g} \mathrm{L} \mathrm{L}^{-1}$ as the maximum permissible concentration for a single pesticide, and values of $0.5 \mu \mathrm{g} \mathrm{L}^{-1}$ and $1-3 \mu \mathrm{g} \mathrm{L} \mathrm{L}^{-1}$ for total pesticides in drinking water and surface waters, respectively. ${ }^{3}$ In Brazil, guidance on concentration limits in environmental waters is provided by Resolution No. 357 (2005) of the National Environment Council (CONAMA), which states maximum permissible values for several substances. However, current legislation does not encompass most of the pesticides currently in use.

It is therefore vital that research is conducted concerning those pesticides that are not yet included in the resolution, but are nonetheless intensively used in agriculture. The fact that these substances are present at trace levels in water demands the use of highly sensitive and reliable analytical techniques for their detection. In response to this need, in recent years there has been increasing interest in sample preparation techniques able to preconcentrate target analytes from the matrix, while minimizing interferences, solvent consumption and costs.

Determination of pesticides in aqueous samples is normally preceded by an extraction step and the commonest techniques employed are liquid-liquid extraction (LLE) or solid phase extraction (SPE). Solid-phase microextraction (SPME) is an attractive alternative option that has seen rapid recent growth in usage, due to the existence of a vast field of potential applications, especially where liquid samples are involved. ${ }^{4}$ The SPME technique offers simple sample preparation, with the elimination of organic solvents minimizing waste generation and occupational exposure. It is extremely fast, versatile, low cost and provides excellent precision. $^{5}$

Gas chromatography coupled with mass spectrometry (GC-MS) is an excellent analytical technique for the determination of thermally stable non-polar or moderately polar compounds, and is especially useful for the simultaneous detection of compounds possessing different chemical properties. ${ }^{6}$

The use of pyrimethanil, ${ }^{7,8}$ pirimicarb $^{9-11}$ and buprofezin ${ }^{12,13}$ at environmental water were based in gas chromatography or high performance liquid chromatography coupled with mass spectrometry (GC and HPLC-MS, respectively). Sample preparation techniques were based at liquid-liquid extraction ${ }^{7}$ and solid-phase extraction, ${ }^{8-13}$ with limits of detection at $\mu g \mathrm{~L}^{-1}$ to $n g \mathrm{~L}^{-1}$ range. However, a few works was applied in analysis of the real water samples with the pesticide studies in the present work.

The objective of this work was to develop and validate a multi-target compound analytical method for the determination of three pesticides (Figure 1) belonging to different chemical groups: pyrimethanil (aniline-pyrimidine),
(1)<smiles>Cc1cc(C)nc(Nc2ccccc2)n1</smiles><smiles>COc1nc(N(C)C)nc(C)c1C</smiles>

(2)

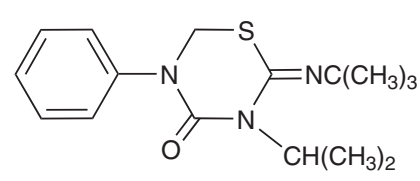

(3)

Figure 1. Chemical structures of the pesticides: (1) pyrimethanil, (2) pirimicarb and (3) buprofezin.

pirimicarb (dimethylcarbamate) and buprofezin (thiadiazine), all of them have been authorized for use by the Brazilian National Health Surveillance Agency (ANVISA). SPME was used for sample extraction and GC-MS for analysis. Samples of surface water for analysis were collected from irrigated regions of northeast Brazil.

\section{Experimental}

\section{Reagents, standards and materials}

Micropearl sodium hydroxide (Synth, Brazil), hydrochloric acid (Nuclear, São Paulo, Brazil) and sodium chloride (Reagen, Rio de Janeiro, Brazil) were all analytical grade. Acetone (Merck, Darmstadt, Germany) was HPLC grade. Ultrapure water was provided from a Milli-Q system (Millipore, Milford, MA, USA).

Stock standard solutions were prepared separately in acetone at concentrations of $100 \mu \mathrm{g} \mathrm{mL}^{-1}$ (pyrimethanil), $280 \mu \mathrm{g} \mathrm{mL}^{-1}$ (pirimicarb) and $150 \mu \mathrm{g} \mathrm{mL}^{-1}$ (buprofezin), and stored at $-18{ }^{\circ} \mathrm{C}$. A working standard solution containing the three pesticides was prepared by dilution of the stock solutions to give final pesticide concentrations of $10 \mu \mathrm{g} \mathrm{L} \mathrm{L}^{-1}$. This solution was used in the optimization experiments and for method validation. The physicochemical properties of the pesticides are provided in Table 1 .

The solid-phase microextraction employed fibers of polydimethylsiloxane (PDMS, 7 and $100 \mu \mathrm{m}$ ), polyacrylate $(\mathrm{PA}, 85 \mu \mathrm{m})$ and polydimethylsiloxane/divinylbenzene (PDMS/DVB, $65 \mu \mathrm{m}$ ), all obtained from Supelco (Bellefonte, PA, USA).

\section{SPME procedure}

Aliquots of $5 \mathrm{~mL}$ of the aqueous samples were conditioned at $\mathrm{pH} 7$ in $10 \mathrm{~mL}$ vials fitted with silicone/Teflon 
Table 1. Physicochemical properties of the pesticides and assessment of the risk of contamination of surface waters using the criteria of Goss

\begin{tabular}{|c|c|c|c|c|c|c|c|c|c|c|}
\hline Pesticide & $\begin{array}{l}\text { Molar mass / } \\
\left(\mathrm{g} \mathrm{mol}^{-1}\right)\end{array}$ & Class & Toxicity $^{\mathrm{a}}$ & $\begin{array}{c}\text { Solubility in } \\
\text { water at } 20^{\circ} \mathrm{C} / \\
\left(\mathrm{mg} \mathrm{L}^{-1}\right)\end{array}$ & $\log \mathrm{K}_{\text {ow }}$ & $\begin{array}{c}\mathrm{K}_{\mathrm{H}} / \\
\left(\mathrm{Pa} \mathrm{m}^{3} \mathrm{~mol}^{-1}, 25^{\circ} \mathrm{C}\right)\end{array}$ & $\mathrm{pKa}$ & $\begin{array}{c}\mathrm{K}_{\mathrm{oc}} / \\
\left(\mathrm{cm}^{3} \mathrm{~g}^{-1}\right)\end{array}$ & $\begin{array}{l}\text { DT50 soil } \\
\text { (days) }\end{array}$ & Goss \\
\hline Pyrimethanil & 199.11 & fungicide & III & 121 & 2.84 & $3.60 \times 10^{-3}$ & 3.52 & 301 & 55 & $\begin{array}{l}\text { MPTAS/ } \\
\text { MPTDW }^{c}\end{array}$ \\
\hline Pirimicarb & 238.39 & insecticide & II & 3100 & 1.7 & $3.30 \times 10^{-5}$ & 4.4 & 388 & 86 & $\begin{array}{l}\text { MPTAS/ } \\
\text { HPTDW }^{\mathrm{c}}\end{array}$ \\
\hline Buprofezin & 305.44 & $\begin{array}{l}\text { insecticide } \\
\text { and acaricide }\end{array}$ & III & 0.46 & 4.93 & $2.8 \times 10^{-2}$ & $\mathrm{nd}^{\mathrm{b}}$ & 2722 & 50 & $\begin{array}{l}\text { HPTAS/ } \\
\text { MPTDW }^{c}\end{array}$ \\
\hline
\end{tabular}

Source: IUPAC; 14 a toxicity: II - moderately toxic; III - slightly toxic; ${ }^{b}$ nd: non-dissociable; ${ }^{\circ} H P T A S$, MPTAS and LPTAS: high, medium and low potential for transport associated with sediment, respectively; HPTDW, MPTDW and LPTDW: high, medium and low potential for transport dissolved in water, respectively.

septum caps. The SPME device containing the fiber (previously conditioned at $280^{\circ} \mathrm{C}$ for $30 \mathrm{~min}$ ) was inserted through the vial septum, and the fiber exposed directly (direct immersion solid-phase microextraction, DI-SPME) in the center of the sample. The sample was agitated with a magnetic stirring bar for $30 \mathrm{~min}$ at $900 \mathrm{rpm}$ and ambient temperature $\left(26^{\circ} \mathrm{C}\right)$. The fiber was then withdrawn into the needle, and the device immediately inserted into the chromatograph injector for desorption of the analytes (7 min at $250^{\circ} \mathrm{C}$ ).

\section{Instrumentation}

During optimization of the extraction method the analytical technique used was gas chromatography with flame ionization detection (GC-FID). A Shimadzu (Kyoto, Japan) Model 17A chromatograph was fitted with a Supelco MDN-5 column $(30 \mathrm{~m} \times 0.25 \mathrm{~mm} \times 0.25 \mu \mathrm{m}$; $5 \%$ phenyl, $95 \%$ dimethylpolysiloxane). The injector temperature was $250^{\circ} \mathrm{C}$, and the splitless time was $2 \mathrm{~min}$. The column oven temperature was initially $80^{\circ} \mathrm{C}$, then ramped to $280{ }^{\circ} \mathrm{C}$ at $10^{\circ} \mathrm{C} \mathrm{min}^{-1}$, with a total analysis time of $20 \mathrm{~min}$. The detector temperature was $300{ }^{\circ} \mathrm{C}$. Helium $(99.995 \%)$ was used as the carrier gas at a flow rate of $1.3 \mathrm{~mL} \mathrm{~min}^{-1}$ (equivalent to a linear velocity of $31.4 \mathrm{~cm} \mathrm{~s}^{-1}$ ). Hydrogen $(99.995 \%)$ and synthetic air (99.997\%) were used as the FID fuel and oxidant gases, respectively. The make-up gas was nitrogen (99.996\%). The chromatograms were recorded and processed using Shimadzu GC Solution software.

A Shimadzu Model QP5050A GC-MS system was used during method validation and sample analyses. The separation column was a J\&W Scientific DB-5 $(30 \mathrm{~m} \times 0.25 \mathrm{~mm} \times 0.25 \mu \mathrm{m} ; 5 \%$ phenyl, $95 \%$ dimethylpolysiloxane). Chromatographic conditions were the same as those described for the GC-FID system. The mass spectrometer detector contained a $70 \mathrm{eV}$ electron ionization source and a quadrupole mass analyzer, operated in scan mode for identification purposes and in selected ion monitoring (SIM) mode for compound quantification. The interface temperature was $280{ }^{\circ} \mathrm{C}$. In the SIM mode the selected ion fragments were $(\mathrm{m} / \mathrm{z}) 183,198$ and 199 (pyrimethanil), 72, 166 and 238 (pirimicarb), and 105, 172 and 305 (buprofezin).

\section{Sampling}

Six water samples were collected from separate irrigation tanks installed at the Platô de Neópolis fruit production project, in the municipality of Neópolis (Sergipe State, Brazil: $10^{\circ} 19^{\prime} 12^{\prime \prime}$ S, $36^{\circ} 34^{\prime} 46^{\prime \prime} \mathrm{W}$ ) on the right hand bank of the São Francisco River. The fruit produced here include mango, acerola, pineapple, papaya, passion fruit, banana, grape, fig, date, kiwi, dwarf coconut, cashew and citrus.

Four water samples were collected from different tanks or irrigation canals at the Distrito de Irrigação Senador Nilo Coelho project (Pernambuco State, Brazil: 09 $14^{\circ}-09^{\circ} 27^{\prime} \mathrm{S}$, $40^{\circ} 50^{\prime}-40^{\circ} 23^{\prime} \mathrm{W}$ ), situated on the left hand bank of the São Francisco River, where the main products are mango and grape. $40 \mathrm{~mL}$ of sample were collected in pre-cleaned flasks at each sampling point. Samples were stored under refrigeration at $4{ }^{\circ} \mathrm{C}$ and extracted within $48 \mathrm{~h}$.

\section{Results and Discussion}

\section{Optimization of extraction parameters (DI-SPME)}

Experiments to determine the best extraction procedure considered the nature of the SPME fiber, sample salinity and $\mathrm{pH}$, agitation speed and times of extraction and desorption. $10 \mu \mathrm{g} \mathrm{L}-1$ concentrations of the pesticides were prepared in $5 \mathrm{~mL}$ aliquots of ultrapure water. All tests were performed in triplicate and the mean values of the GC-FID chromatogram peak areas calculated. 


\section{Selection of fiber and extraction mode}

The extraction efficiencies of the PDMS ( 7 and $100 \mu \mathrm{m}), \mathrm{PA}(85 \mu \mathrm{m})$ and PDMS/DVB $(65 \mu \mathrm{m})$ fibers were compared in direct extraction mode using an agitation speed of $900 \mathrm{rpm}$ at ambient temperature $\left(26^{\circ} \mathrm{C}\right)$ and with an extraction time of $30 \mathrm{~min}$. The fibers were pre-conditioned in the chromatograph injector, using the times and temperatures recommended by the manufacturer (which are specific to each type of fiber). Only the $100 \mu \mathrm{m}$ PDMS fiber showed a response for the three pesticides, with the largest signal obtained for buprofezin (Figure 2), so this fiber was used in all subsequent experiments. The PA fiber should be in principle the most efficient for pirimicarb, since the compound is highly soluble in water and has a low $\mathrm{K}_{\mathrm{ow}}$ compared to the other pesticides. However, fiber selection cannot rely solely on the physicochemical properties of the compounds. The complex processes of adsorption/ desorption of the pesticides by the fibers are not governed only by considerations of solubility or hydrophobicity. ${ }^{15}$

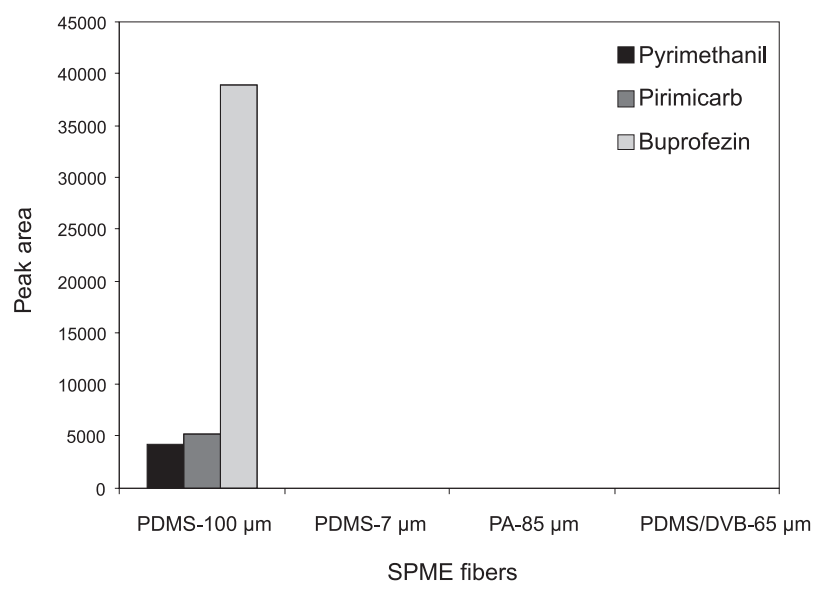

Figure 2. Determination of extraction efficiencies (in direct mode) using different types of SPME fiber.

The direct (DI-SPME) and headspace (HS-SPME) extraction modes were compared. The DI-SPME technique is normally more sensitive and is the method of choice for analysis of clean aqueous samples. ${ }^{16}$ The headspace mode gave no signal for the pesticides studied, which are quite involatile as shown by their low Henry's constant $\left(\mathrm{K}_{\mathrm{H}}\right)$ values (Table 1). Hence, direct extraction using the $100 \mu \mathrm{m}$ PDMS fiber was employed in further development of the method.

\section{Sample agitation}

The quantity of analyte extracted depends on the speed with which the SPME process achieves equilibrium in mass transfer between the aqueous phase and the fiber. ${ }^{17}$ Agitation speeds of 300, 900 and 1200 rpm were tested, and the best extraction efficiency was achieved at $900 \mathrm{rpm}$ (Figure 3). At higher speed there was a reduction in the extraction of pirimicarb, while pyrimethanil showed no change in extraction efficiency according to agitation speed. Buprofezin did not achieve equilibrium at speeds up to $1200 \mathrm{rpm}$, however higher speeds did not improve the extraction efficiencies of the other compounds.

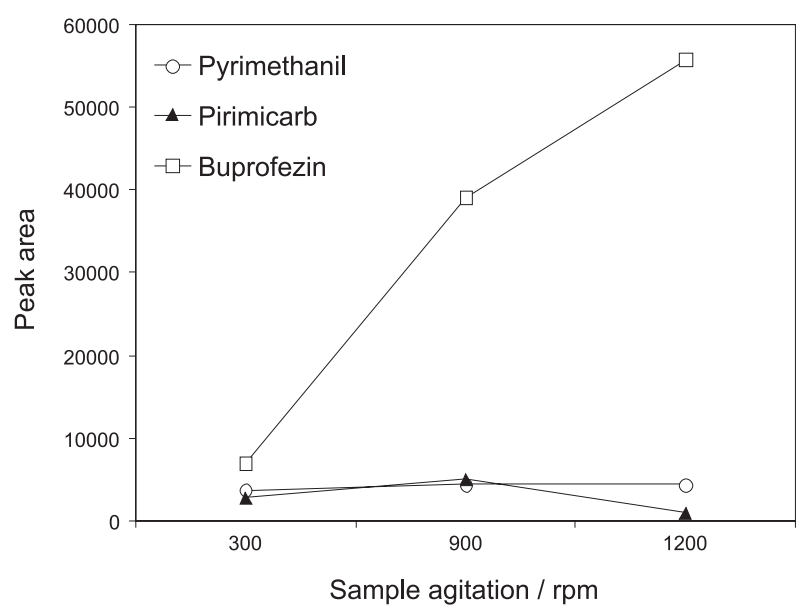

Figure 3. Influence of the agitation speed on extraction.

\section{Desorption time}

A high temperature or a long desorption time is usually needed to ensure complete desorption of analytes extracted by the fiber. The SPME method may be influenced by carryover due to incomplete desorption, especially when the analytes have high affinity for the fiber coating. ${ }^{18}$

Desorption periods between 1 and $10 \mathrm{~min}$ were used in order to determine the time required for complete analyte desorption at an injector temperature of $250^{\circ} \mathrm{C}$. A memory effect was observed for buprofezin (using a concentration of $10 \mu \mathrm{g} \mathrm{mL}^{-1}$ ). The residual amounts remaining after $5 \mathrm{~min}$ of desorption were less than 5\%, so a desorption time of 7 min was chosen to ensure full release of the compounds.

\section{Effect of sample $\mathrm{pH}$}

When the affinity of an adsorbent for an analyte is determined primarily by hydrophobic interactions, it can be enhanced by maintaining the analyte molecules in a nonionized form. ${ }^{18}$ The influence of $\mathrm{pH}$ (at values of $3,4,5,6$, 7,8 and 9) on the efficiency of extraction of the pesticides was investigated using an extraction time of $30 \mathrm{~min}$ without any salt addition. For pyrimethanil and buprofezin, the extraction efficiency reduced significantly at acid $\mathrm{pH}$, with no extraction achieved at $\mathrm{pH} \leq 5$ (Figure 4). According to its 
pKa value (Table 1), at acid $\mathrm{pH}$ the pyrimethanil molecule exists in ionized form, hence hindering interaction with the PDMS fiber. Nakamura and Daishima ${ }^{19}$ reported that buprofezin was clearly decomposed under acidic conditions in aqueous solution.

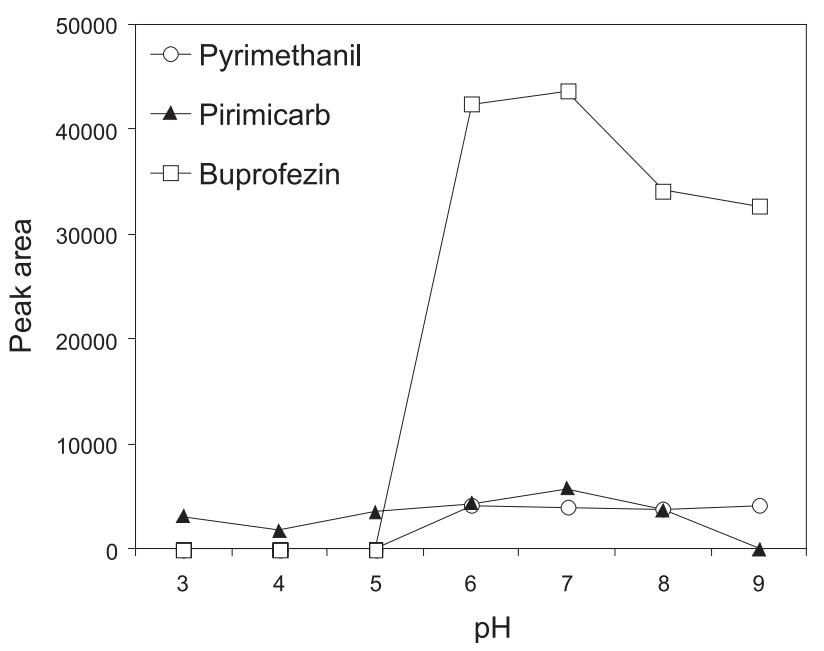

Figure 4. Influence of the $\mathrm{pH}$ value on extraction.

Varying the $\mathrm{pH}$ between 6 and 9 produced, no noticeable change in extraction of pyrimethanil was observed, however extraction of buprofezin and pirimicarb was reduced under alkaline conditions (at pH 8 and 9). In light of these observations, an optimized $\mathrm{pH} 7$ was adopted. In previous work, pyrimethanil and pirimicarb, as well as other pesticides, were extracted more efficiently at $\mathrm{pH} 7$ from samples of grapes and apples. ${ }^{20}$ In a study for four organosulfur insecticides present in water, buprofezin was also found to be more readily extracted at $\mathrm{pH} 7{ }^{21}$

\section{Extraction time}

The influence of extraction time $(1,5,10,20,30$ or $60 \mathrm{~min})$ was investigated after optimization of the above described parameters. Pirimicarb and pyrimethanil reached states of equilibrium after around $10 \mathrm{~min}$, while the extraction of buprofezin continued to increase even after $60 \mathrm{~min}$ (Figure 5). This can be explained, at least in part, by the high molar mass of buprofezin, compared to the other two pesticides (Table 1). High molecular weight compounds require longer equilibration times due to their smaller diffusion coefficients, since the time required to reach equilibrium is inversely proportional to the diffusion coefficient. ${ }^{22}$

For analytical purposes, it is not essential to reach equilibrium, however method parameters (including extraction time, agitation speed and fiber position in the vial) need to be carefully controlled to avoid inaccuracies. ${ }^{23}$ An extraction time of $30 \mathrm{~min}$ was chosen here to provide a

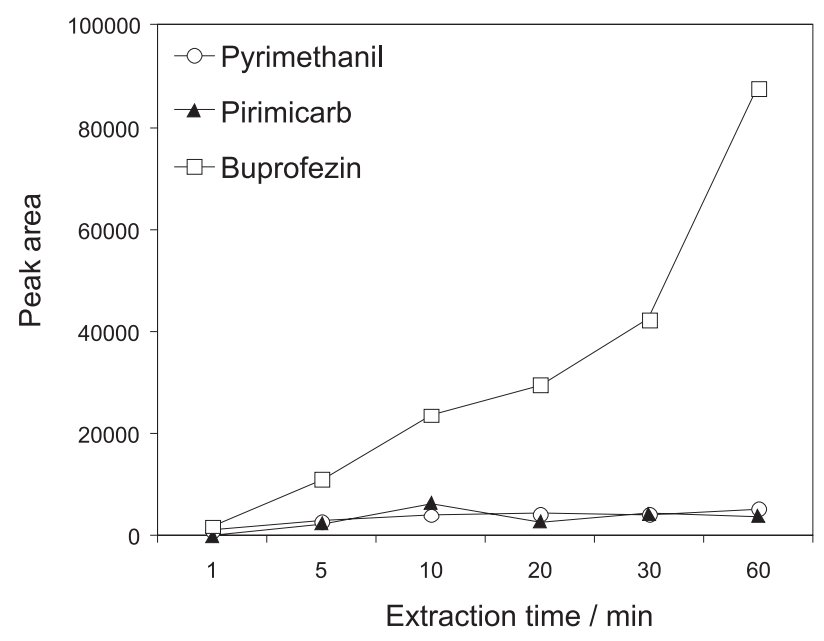

Figure 5. Influence of extraction time on efficiency of the method.

good efficiency of extraction of all three pesticides without introducing unduly long analysis times.

Ionic strength

The increase of the ionic strength of the medium can increase pesticide extraction efficiency, and the salting-out effect is especially effective for highly polar compounds. ${ }^{24}$ Sodium chloride $(\mathrm{NaCl})$ was added to the solutions at concentrations of 1 and $3 \%(\mathrm{~m} / \mathrm{v})$. None of the pesticides studied showed any significant increase of the extraction efficiency in the presence of $\mathrm{NaCl}$, so its usage was not considered further. Higher $\mathrm{NaCl}$ concentrations were not employed due to possible reduction of the useful lifetimes of the fibers by formation of salt crystals on the surfaces..$^{25}$ Similar conclusions have been reached in other studies. ${ }^{20,26}$

\section{Validation of the method}

After defining the optimized SPME conditions, the method was validated according to the procedure described in the Experimental section. Validation considered robustness, linearity and precision parameters and limits of detection and quantification.

Robustness was assessed using a full $2^{4}$ factorial design, with small adjustments of extraction time (29 and $31 \mathrm{~min}$ ), desorption time (6 and $8 \mathrm{~min}), \mathrm{pH}$ (6 and 8 ) and agitation speed (800 and $1000 \mathrm{rpm})$. A total of 18 experiments were performed, two of which were undertaken at the central point between the two levels in order to estimate experimental repeatability (Table 2). The tests were conducted in a random sequence, and the results expressed as the pesticide peak areas. The obtained Pareto diagrams showed that the alterations of the experimental parameters caused no significant differences in the responses, for all 
three pesticides. The results obtained for buprofezin are shown in Figure 6. The method can therefore be considered to be robust with respect to the parameters examined.

Table 2. Variables, levels and matrix for evaluation of robustness using a full $2^{4}$ factorial design

\begin{tabular}{|c|c|c|c|c|}
\hline \multirow{2}{*}{\multicolumn{2}{|c|}{ Variable }} & \multicolumn{3}{|c|}{ Level } \\
\hline & & Low $(-1)$ & Central (0) & $\operatorname{High}(+1)$ \\
\hline \multicolumn{2}{|c|}{ (A) Agitation speed / rpm } & 800 & 900 & 1000 \\
\hline \multicolumn{2}{|l|}{ (B) $\mathrm{pH}$} & 6 & 7 & 8 \\
\hline \multicolumn{2}{|c|}{ (C) Extraction time / min } & 29 & 30 & 31 \\
\hline \multicolumn{2}{|c|}{ (D) Desorption time / min } & 6 & 7 & 8 \\
\hline Experiment & $\mathrm{A}$ & $\mathrm{B}$ & $\mathrm{C}$ & $\mathrm{D}$ \\
\hline 1 & -1 & -1 & -1 & -1 \\
\hline 2 & -1 & -1 & 1 & -1 \\
\hline 3 & -1 & 1 & -1 & -1 \\
\hline 4 & -1 & 1 & 1 & -1 \\
\hline 5 & -1 & -1 & 1 & -1 \\
\hline 6 & 1 & -1 & 1 & -1 \\
\hline 7 & -1 & 1 & 1 & -1 \\
\hline 8 & 1 & 1 & 1 & -1 \\
\hline 9 & -1 & -1 & -1 & 1 \\
\hline 10 & 1 & -1 & -1 & 1 \\
\hline 11 & -1 & 1 & -1 & 1 \\
\hline 12 & 1 & 1 & -1 & 1 \\
\hline 13 & -1 & -1 & 1 & 1 \\
\hline 14 & 1 & -1 & 1 & 1 \\
\hline 15 & -1 & 1 & 1 & 1 \\
\hline 16 & 1 & 1 & 1 & 1 \\
\hline 17 & 0 & 0 & 0 & 0 \\
\hline 18 & 0 & 0 & 0 & 0 \\
\hline
\end{tabular}

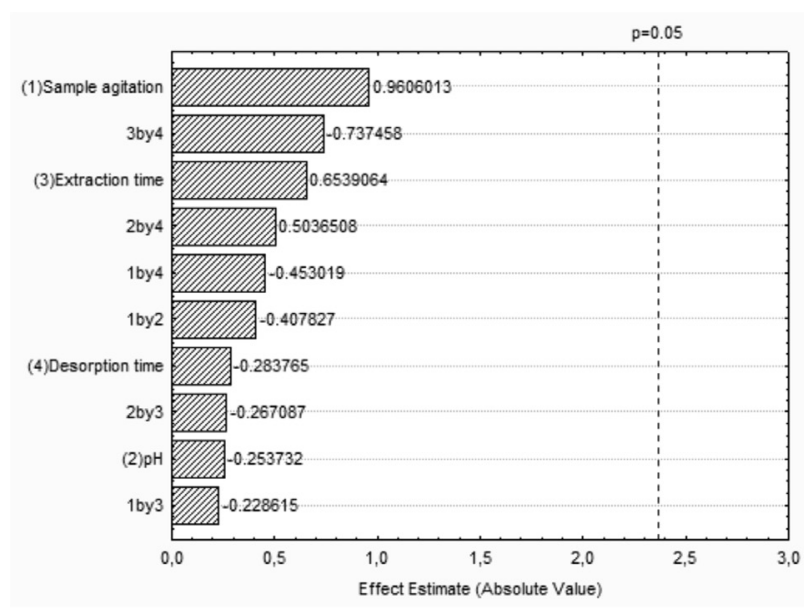

Figure 6. Factorial design Pareto diagram for assessment of the robustness of the method (for buprofezin).
The results obtained for the validation parameters are provided in Table 3. Linearity was determined in the concentration range $0.1-4.0 \mu \mathrm{g} \mathrm{L}^{-1}$, employing seven concentration levels (in duplicate). The coefficients of determination $\left(\mathrm{R}^{2}\right)$ were greater than 0.991 .

The method precision was measured as the repeatability obtained for the analysis of seven replicates at analyte concentrations of $0.2 \mu \mathrm{g} \mathrm{L}^{-1}$ in ultrapure water. The values obtained were $5.0 \%$ (pyrimethanil), $9.6 \%$ (buprofezin) and $14.7 \%$ (pirimicarb), which were considered satisfactory.

The detection limit was calculated as the concentration that produced a signal three times larger than the average baseline noise, measured using the sample blank. The limit of quantification (LOQ) was defined as the lowest concentration in which the analytes could be measured with an RSD lower than $20 \%$. The values obtained were below those required by the European Community $\left(1-3 \mu \mathrm{g} \mathrm{L}^{-1}\right)$ for analyses of surface waters.

\section{Analysis of environmental samples}

Assessment of the theoretical potential for the pesticides to contaminate surface waters was initially performed, using the criteria proposed by Goss. ${ }^{27}$ These criteria are based on the compound classification into two groups, those that can be transported dissolved in water, and those that are transported associated with suspended sediment. The method considers the half-life of the compound in soil $\left(\mathrm{DT}_{50}\right.$ in soil), its solubility in water and the constant of adsorption by soil organic matter $\left(\mathrm{K}_{\mathrm{oc}}\right)$. Pesticides are classified as having high, medium or low potential for transport associated with the sediment or dissolved in water, using these physicochemical parameters.

According to the criteria of Goss (Table 1), buprofezin shows high potential for transport associated with suspended sediment (HPTAS). Pyrimethanil and pirimicarb showed medium potential for sediment-associated transport (MPTAS), which was the principle mechanism for their transport in surface waters. In the case of transport dissolved in water, buprofezin and pyrimethanil showed medium potential (MPTDW), while pirimicarb showed high potential (HPTDW).

Following validation, the method was applied in analysis of the surface water samples collected from the irrigated

Table 3. Results of validation of the proposed SPME method for the pesticides studied $(n=7)$

\begin{tabular}{lcccccc}
\hline Pesticide & Linear range / $\left(\mu \mathrm{g} \mathrm{L}^{-1}\right)$ & Linear regression equation & $\mathrm{R}^{2}$ & Precision / $(\mathrm{RSD}, \%)$ & $\left.\mathrm{LOD} /(\mu \mathrm{g} \mathrm{L})^{-1}\right)$ & $\mathrm{LOQ} /(\mu \mathrm{g} \mathrm{L}-1)$ \\
\hline Pyrimethanil & $0.1-4.0$ & $\mathrm{y}=529385 \mathrm{x}+60943$ & 0.999 & 5.0 & 0.05 & 0.10 \\
Pirimicarb & $0.2-4.0$ & $\mathrm{y}=4426 \mathrm{x}+8499$ & 0.997 & 14.7 & 0.10 & 0.20 \\
Buprofezin & $0.1-4.0$ & $\mathrm{y}=440006 \mathrm{x}-20753$ & 0.991 & 9.6 & 0.04 & 0.10 \\
\hline
\end{tabular}


areas. Four within ten samples contained detectable pesticides, as shown in the obtained chromatograms (Figure 7). Buprofezin was found in two samples from Platô de Neópolis, one at a concentration of $0.14 \mu \mathrm{g} \mathrm{L}^{-1}$ and the other one below the LOQ. Pirimicarb was detected in two samples from Distrito de Irrigação Senador Nilo Coelho, at concentrations below the LOQ. Pyrimethanil was not detected in any of the analyzed samples. All the pesticide concentrations were below the European Community limit values for surface waters. The results were generally in agreement with the preliminary analysis by the method of Goss, in which buprofezin and pirimicarb were classified as HPTAS and HPTDW, respectively.

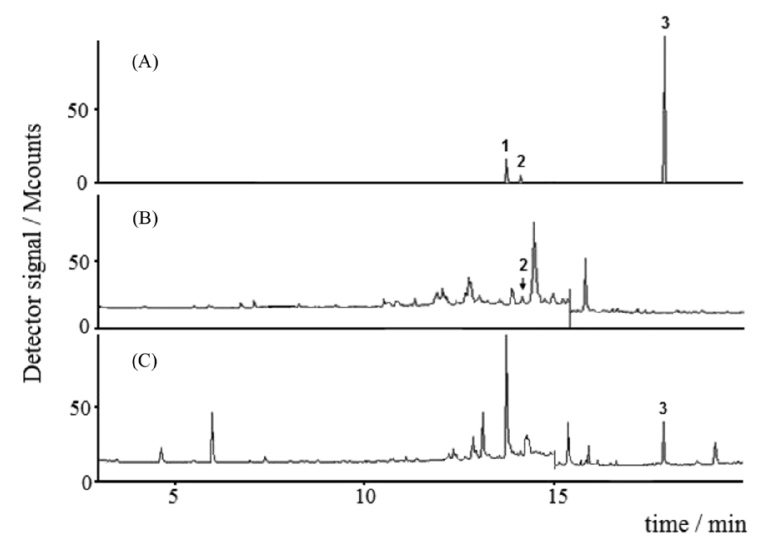

Figure 7. Chromatograms obtained using DI-SPME/GC-MS (A): pesticides $\left(5 \mu \mathrm{g} \mathrm{L}^{-1}\right)$ in ultrapure water; (B) and (C): samples containing concentrations $<\mathrm{LOQ}$ and $0.14 \mu \mathrm{g} \mathrm{L}^{-1}$, respectively, $\mathbf{1}=$ pyrimethanil; $\mathbf{2}$ = pirimicarb; $\mathbf{3}=$ buprofezin .

Pyrimethanil, pirimicarb and buprofezin have been analyzed in surface waters in several earlier studies. ${ }^{8,26,28}$ The average concentrations obtained were $0.19 \mu \mathrm{g} \mathrm{L}^{-1}$ (buprofezin), $0.003 \mu \mathrm{g} \mathrm{L}^{-1}$ (pirimicarb) and $0.019 \mu \mathrm{g} \mathrm{L}^{-1}$ (pyrimethanil). Other research at Platô de Neópolis has identified the presence of other pesticides, including methyl parathion, bifenthrin, pyraclostrobin and azoxystrobin, in surface waters of the region. ${ }^{16,29}$

\section{Conclusions}

An analytical method employing DI-SPME and GC-MS was developed for the determination of three pesticides (pyrimethanil, pirimicarb and buprofezin), belonging to different chemical classes, in agricultural irrigation waters. Optimization of the SPME extraction efficiency was shown to be crucial in improving the sensitivity of the technique. The quantification limits achieved $\left(0.1-0.2 \mu \mathrm{g} \mathrm{L}^{-1}\right)$ were lower than the European Community limit values for surface waters. The presence of buprofezin and pirimicarb was detected in water samples, demonstrating that pesticides applied in fruit plantations could contaminate surface hydric systems.

\section{Acknowledgments}

The authors thank the Banco do Nordeste do Brasil (Convênio BNB/ETENE/UFS) for financial support (process no. 2346/07-01) and the Universidade Federal do Vale do São Francisco, Petrolina Campus for enabling Clóvis Fernandes de Sá Filho to undertake postgraduate research.

\section{References}

1. Silva, D. R. O.; Avila, L. A.; Agostinetto, D.; Magro, T. D.; Oliveira, E.; Zanella, R.; Noldin, J. A.; Cienc. Rural 2009, 39, 2383.

2. http://www. portal.anvisa.gov.br accessed in July 2010.

3. López-Blanco, C.; Gómez-Álvarez, S.; Rey-Garrote, M.; Cancho-Grande, B.; Simal-Gándara, J.; Anal. Bioanal. Chem. 2006, 384, 1002.

4. Goncalves, C.; Alpendurada, M. F.; J. Chromatogr., A 2002, 963, 19.

5. Costa, L. L. F.; Sant'ana, E. S.; Suchara, E. A.; Benato, V. S.; Carasek, E.; Quim. Nova 2008, 31, 79.

6. Sabin, G. P.; Prestes, O. D.; Adaime, M. B.; Zanella, R.; J. Braz. Chem. Soc. 2009, 20, 918.

7. Gómez, M. J.; Gómez-Ramos, M. M.; Agüera, A.; Mezcua, M.; Herrera, S.; Fernández-Alba, A. R.; J. Chromatogr., A 2009, 1216, 401.

8. Rodrigues, A. M.; Ferreira, V.; Cardoso, V. V.; Ferreira, E.; Benoliel, M. J.; J. Chromatogr., A 2007, 1150, 267.

9. Pitarch, E.; Portolés, T.; Marín, J. M.; Ibáñez, M.; Albarrán, F.; Hernández, F.; Anal. Bioanal. Chem. 2010, 397, 2763.

10. Mansilha, C.; Melo, A.; Rebelo, H.; Ferreira, I. M. P. L. V. O.; Pinho, O.; Domingues, V.; Pinho, C.; Gameiro, P.; J. Chromatogr., A 2010, 1217, 6681.

11. Carabias-Martínez, R.; García-Hermida, C.; RodríguezGonzalo, E.; Ruano-Miguel, L.; J. Sep. Sci. 2005, 28, 2130.

12. Tanabe, A.; Kawata, K.; Bull. Environ. Contam. Toxicol. 2009, 82,705 .

13. Hernández, F.; Sancho, J. V.; Pozo, O.; Lara, A.; Pitarch, E.; J. Chromatogr., A 2001, 939, 1.

14. http://sitem.herts.ac.uk/aeru/iupac/index.htm accessed in July 2010.

15. Lambropoulou, D. A.; Konstantinou, I. K.; Albanis, T. A.; J. Chromatogr., A 2000, 893, 143.

16. Filho, A. M.; dos Santos, F. N.; Pereira, P. A. P.; Microchem. J. 2010, 96, 139.

17. Goncalves, C.; Alpendurada, M. F.; J. Chromatogr., A 2002 , 968, 177. 
18. Pawliszyn, J.; Solid Phase Microextraction: Theory and Practice, $1^{\text {st }}$ ed., Wiley-VCH: New York, 1997.

19. Nakamura, S.; Daishima, S.; Anal. Bioanal. Chem. 2005, 382, 99.

20. Amvrazi, E. G.; Tsiropoulos, N. G.; J. Chromatogr., A 2009 , 1216, 7630.

21. Zhao, Y. L. E.; Zhu, W.; Gao, H.; Zhou, Z.; J. Chromatogr., A 2009, 1216, 885 .

22. Scheyer, A.; Morville, S.; Mirabel, P.; Millet, M.; Anal. Bioanal. Chem. 2006, 384, 475.

23. Yao, Z. W.; Jiang, G. B.; Liu, J. M.; Cheng, W.; Talanta 2001, $55,807$.

24. Eisert, R.; Levsen, K.; J. Am. Soc. Mass Spectrom. 1995, 6, 1119.
25. Berrada, H.; Font, G.; Molto, J. C.; J. Chromatogr., A 2000 , $890,303$.

26. Giordano, A.; Fernández-Franzón, M.; Ruiz, M. J.; Font, G.; Picó, Y.; Anal. Bioanal. Chem. 2009, 393, 1733.

27. Goss, D.W.; Weed Technol. 1992, 6, 701.

28. Planas, C.; Puig, A.; Rivera, J.; Caixach, J.; J. Chromatogr., A 2006, 1131, 242.

29. Pinheiro, A. S.; de Andrade, J. B.; Talanta 2009, 79, 1354.

Submitted: September 14, 2010

Published online: March 29, 2011 